\section{Preference for tones as a function of frequency (hertz) and intensity (decibels)*}

\author{
PAUL C. VITZ† \\ New York University, New York, New York 10003
}

An extension of the Wundt hypothesis concerning stimulus intensity and hedonic tone leads to the prediction that $S$ s prefer tones of intermediate frequency (hertz) and of intermediate intensity (decibels). In Experiment 1. tones varying from 60 to $5000 \mathrm{~Hz}$ were presented in a paired comparison procedure, and, as predicted, Ss' preference was an inverted-U-shaped function Jf frequency, with the most preferred tones in the range of $400-750 \mathrm{~Hz}$. In Experiment 2, tones varying in intensity from 40 to $90 \mathrm{~dB}$ were also presented in a paired comparison procedure, and again the predicted inverted-U-shaped preference function was found, with $50 \mathrm{~dB}$ as the preferred intensity. Related research and some unexpected findings are discussed.

It was Wundt (1874, p. 468) who first postulated that affect, or hedonic state, was related to stimulus intensity in the simple way shown in Fig. 1 . This function, roughly shaped like a skewed and inverted $U$, has received support primarily from studies on the taste dimensions of sourness, saltiness, bitterness, and sweetness. Engle (1928) had human Ss rate the pleasantness of solutions having one of these properties and found curves for sourness, saltiness, and bitterness very consistent with Wundt's hypothesis. Pfaffmann (1960) also found similar curves using rats as Ss. The dimension of sweetness was something of an exception in both studies since neither investigator found good evidence for a decline in preference for sweetness at high levels of concentration.

Wundt's hypothesis is restricted to simple stimulus intensity; however, if one moves to the general but less precise dimensions of stimulus complexity, variation, novelty, etc., then there are many theorists who have predicted that humans and animals prefer a moderate amount of stimulation: Berlyne $(1960,1967)$, Dember and Earl (1957), Fiske and Maddi (1961), and especially in the case of lower animals, Schneirla (1959, 1965). This general theoretical position represents a major development in the combined areas of motivation, reinforcement, and attention. Evidence supporting this position of direct relevance to the present study is reported by several investigators. Vitz (1966) found that human Ss had a definite preference for

\footnotetext{
*This work was supported by the New York University Arts and Sciences Fund and by a New York University-NSF institutional grant. The assistance of Deborah Miller in data collection and analysis was invaluable. tAddress: Department of Psychology, New York University, 707 Broadway, New York, New York 10003.
}

sequences of tones sounding like simple music that presented moderate amounts of variation. Stimulus variation was presented on the dimensions of tone frequency, intensity, and duration. Boesch, Baltes, and Schmidt (1968) presented a $1000-\mathrm{Hz}$ tone with an intensity of $55-60 \mathrm{~dB}$ at rates ranging from .3 to $10 / \mathrm{sec}$; they found that Ss had a preferred rate of tone stimulation. The many other studies providing evidence in support of the "moderate stimulation" position are thoroughly integrated and summarized by Berlyne (1967).

The purpose of the present study is dimensions of sound frequency (hertz) to test Wundt's hypothesis on the postulated by Wundt (1874). and intensity (decibels). Applying the hypothesis to sound frequency is a modest extension of the original, since, in the language of Stevens (1957), the hypothesis has been extended from prothetic continua to a metathetic continuum. In addition, the present study is a very elementary experiment in aesthetics. Pure tones are extremely simple aesthetic stimuli, but nevertheless our reactions to individual tones must be some part of our total reaction to music. Of more importance is the fact that the hypothesis being tested can be interpreted as a special case of a general theoretical position already shown to have wide support and including the evidence that humans prefer moderate variation and moderate rates in tone sequences. The possibility of deriving affective response to individual pure tones from the same general theory used to derive responses to more complex tone sequences would certainly broaden the significance of the results for a theory of aesthetics.

\section{EXPERIMENT 1 TONE FREQUENCY Method}

Subjects. Sixteen university students, eight male and eight female, served as Ss. All Ss reported that to the best of their knowledge they had normal hearing, but no tests were made for possible unknown hearing abnormalities.

Stimuli. Eight tones were selected

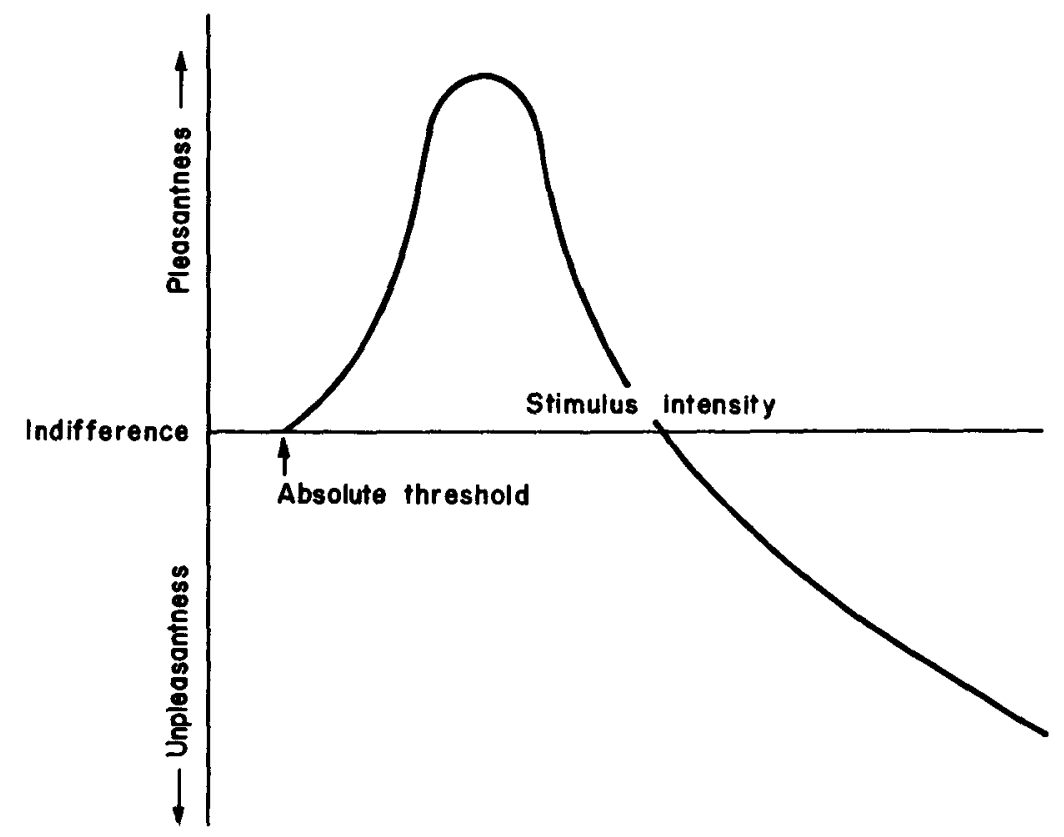

Fig. 1. The theoretical relation between stimulus intensity and affect as 
Table 1

Percent Preference for Each Tone Frequency Averaged Across All Intensities

Tone Frequency $(\mathrm{Hz})$

\begin{tabular}{|c|c|c|c|c|c|c|c|c|}
\hline $\mathbf{S}$ & 60 & 110 & 210 & 400 & 750 & 1410 & 2660 & 5000 \\
\hline 1 & 71.4 & 71.4 & 50.0 & 66.7 & 47.6 & 42.9 & 33.3 & 16.7 \\
\hline 2 & 11.9 & 45.2 & 83.3 & 92.9 & 88.1 & 47.6 & 23.8 & 7.1 \\
\hline$\overline{3}$ & 19.0 & 45.2 & 73.8 & 85.7 & 78.6 & 40.4 & 40.4 & 16.7 \\
\hline 4 & 0.0 & 16.7 & 40.4 & 90.4 & 97.6 & 64.3 & 54.8 & 35.7 \\
\hline 5 & 52.4 & 66.7 & 66.7 & 80.9 & 57.1 & 38.1 & 28.6 & 9.5 \\
\hline 6 & 4.8 & 33.3 & 64.3 & 85.7 & 80.9 & 71.4 & 45.2 & 14.3 \\
\hline 7 & 26.2 & 66.7 & 83.3 & 88.1 & 66.7 & 30.9 & 33.3 & 4.8 \\
\hline 8 & 0.0 & 19.0 & 69.0 & 90.4 & 85.7 & 64.3 & 45.2 & 26.2 \\
\hline 9 & 73.8 & 38.1 & 42.9 & 35.7 & 71.4 & 54.8 & 50.0 & 33.3 \\
\hline 10 & 52.4 & 73.8 & $\mathbf{8 0 . 9}$ & 78.6 & 66.7 & 26.2 & 19.0 & 2.4 \\
\hline 11 & 16.7 & 42.9 & 54.8 & 88.1 & 85.7 & 54.8 & 42.9 & 14.3 \\
\hline 12 & 2.4 & 19.0 & 52.4 & 85.7 & 90.4 & 73.8 & 47.6 & 28.6 \\
\hline 13 & 2.4 & 11.9 & 42.9 & 76.1 & 85.7 & 66.7 & 64.3 & 50.0 \\
\hline 14 & 4.8 & 9.5 & 28.6 & 47.6 & 85.7 & 73.8 & 76.1 & 73.8 \\
\hline 15 & 9.5 & 14.3 & 54.8 & 85.7 & 88.1 & 59.5 & 52.4 & 35.7 \\
\hline 16 & 7.1 & 26.2 & 40.4 & 69.0 & 85.7 & 52.4 & 66.7 & 52.4 \\
\hline $\begin{array}{l}\text { Mean } \\
\text { Percent }\end{array}$ & 22.2 & 37.5 & 58.0 & 77.9 & 78.8 & 53.9 & 45.2 & 26.3 \\
\hline
\end{tabular}

for the paired comparison task: 60 , $110,210,400,750,1410,2660$, and $5000 \mathrm{~Hz}$. These tones were selected to cover the range of $60-5000 \mathrm{~Hz}$, the most important range for human hearing. The intervals between tones were within a few cycles of equal log units. The tones were pure tones generated on two Hewlett-Packard audio oscillators, Model 200AB.

Intensities were controlled by two Hewlet $t$-Packard attenuators, Model 350D, and were measured and equated within $\pm 1 \mathrm{~dB}$. Intensities were measured and standardized before each experimental session. A General Radio Company precision sound-level meter (Type 1561-A) was used in conjunction with a General Radio Company precision microphone (Type 1560-P7) for measuring and equating intensities at the earphone, Headsets were U.S. Government general issue.

Each of the eight tones was presented at one of three inten. sities: 65,75 , and $85 \mathrm{~dB}$ (re .0002 dynes $/ \mathrm{cm}^{2}$ )

Procedure. Each $\mathbf{S}$ was presented with 168 pairs of tones and asked to choose the tone he found most pleasant; a tone lasted 1.0 sec. These 168 comparisons consisted of three groups of 56 tones. Each group of 56 tones consisted of all the possible paired comparisons among eight tones, all at the same intensity. Each pair of tones was presented twice, in the order $a-b$ and $b-a$ to control for order effects. The three groups of 56 comparisons at a fixed intensity were intermixed so as to distribute each intensity in about equal proportions over the 168 trials. In addition, the Ss received different and counterbalancing orders of presentation. After 84 trials, there was a 5- to 10-min break.

At the end of the experiment, the $S$ filled out a short questionnaire asking (1) How would you rate your interest in music? (a) indifferent to music; (b) little interest; (c) moderate interest; (d) strong interest; (e) very strong interest. (2) How much time do you spend listening attentively to music? (a) none at all; (b) a little; (c) a moderate amount; (d) a great deal of time. (3) How much formal music training have you had other than in required, general music courses? (a) none at all; (b) 1 year or less; (c) 2 to 3 years; (d) more than 3 years, please list the instrument(s) in which you had this formal training (e.g., voice, piano, etc.).

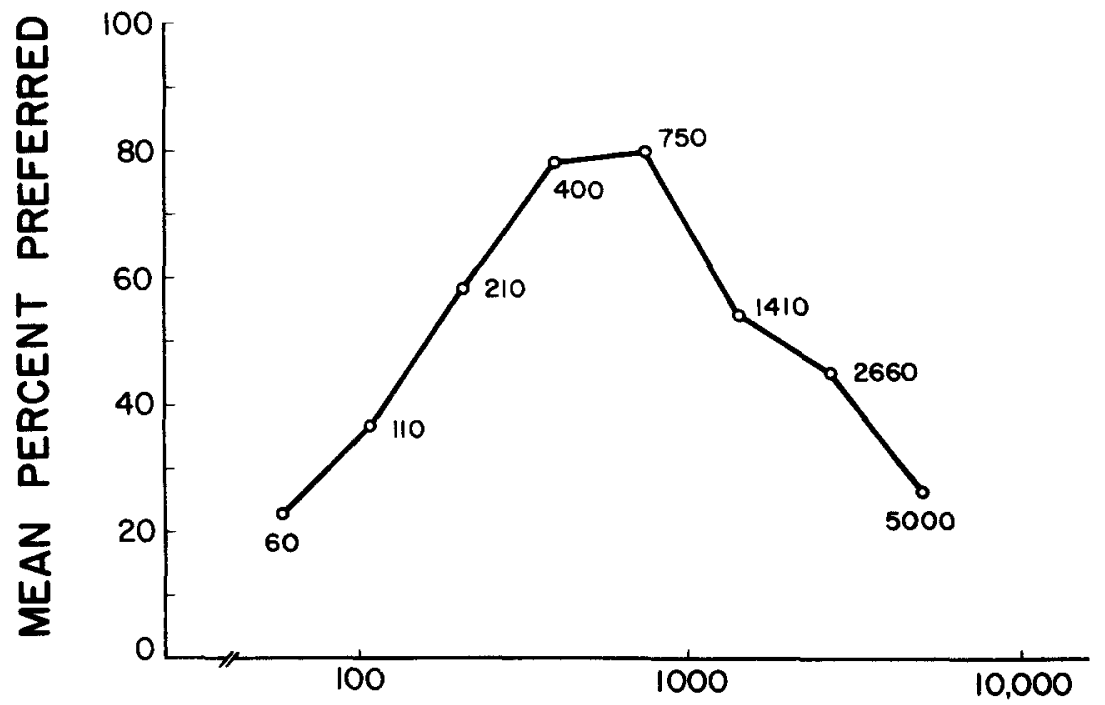

\section{TONE FREQUENCY (Log Scale)}

Fig. 2. Preference for tones as a function of tone frequency (hertz). Data points are the mean percent each tone was preferred in comparison to the others.
The major results are shown in Table 1 and Fig. 2. From Fig. 2 it is clear that the average preferred frequency is around $750 \mathrm{~Hz}$ and that preference declines regularly on both sides of the peak point.

Table 1 presents the proportion of times each frequency was selected for each S. These results show that the great majority of Ss have preference curves very similar to the average curve. One $S$, No. 9, shows two "peak" points.

Further evidence supporting the hypothesis is presented in Fig. 3 by breaking the results into three sets of preferences, one each at 65,75 , and 85 dB. Again, the Ss show curves with peak preferences in the middle range. Looking at the results of individual Ss, we found that at $65 \mathrm{~dB} 12 \mathrm{Ss}$ had individual curves regularly rising to a peak and then declining regularly; at $75 \mathrm{~dB} 7 \mathrm{Ss}$ had such regular curves and at $85 \mathrm{~dB}, 10 \mathrm{Ss}$. Obviously, reducing the data by two-thirds means that chance effects could easily have caused the small reversals in the predicted curves. Evidence for this interpretation is that of the 19 curves which contained a reversal 12 would have matched the predicted curve without a reversal if a single choice had been changed. Thus, the predicted curve characterizes both the average curve and the individual $S$ curves at each of the three different intensities.

An unexpected finding can be seen in Fig. 3, which shows that as the intensity of the paired tones increased the preferred frequency also increased. 


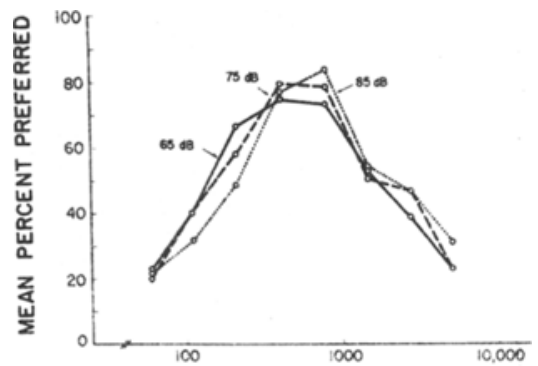

TONE FREQUENCY (Log Scale)

Fig. 3. Preference for tones as a function of frequency at three different levels of intensity (decibels).

The mean preferred frequencies were 454 at $65 \mathrm{~dB}, 616$ at $75 \mathrm{~dB}$, and 731 at $85 \mathrm{~dB}$. The difference of 277 between the preference at 65 and $85 \mathrm{~dB}$ is significant $(t=1.78, \mathrm{p}<.05$, one-tailed, $\mathrm{df}=15$ ). This finding is considerably more significant if an analysis is done of the individual choices. When the pair of tones was $65 \mathrm{~dB}$, the higher frequency was selected $45 \%$ of the time, at $75 \mathrm{~dB}$, $48 \%$ of the time, and at $85 \mathrm{~dB}$ the higher frequency was selected $54 \%$ of the time. The difference between the percent at 65 and $85 \mathrm{~dB}$ is quite significant $(t=2.75, \quad p<.02$, two-tailed, $\mathrm{df}=15$ ).

On the basis of their answers to the three questions, the $S$ s were divided into a high and a low music group. The high music group consisted of the eight Ss who scored highest on the three questions. No differences were found between the high and low music Ss or between the first and last parts of the experiment; nor were any sex differences found.

\section{EXPERIMENT 2 TONE INTENSITY Method}

Subjects. Sixteen new Ss with the same characteristics as those in Experiment 1 were used.

Stimuli. Six different intensities: $40,50,60,70,80$, and $90 \mathrm{~dB}$ were selected. The same stimulus-generating equipment was used as in Experiment 1, except that new and more comfortable headsets were used. Each intensity was presented at one of the following frequencies: 100,400 , 1400 , and $5000 \mathrm{~Hz}$.

Procedure. Each $\mathbf{S}$ was presented with 120 pairs of intensities and asked to choose the one he found most pleasant. These 120 comparisons consisted of four groups of 30 tones. Each group of 30 consisted of all the possible paired comparisons among six intensities at each of the four frequencies; i.e., each pair of intensities was presented twice, in the order $a-b$ and $b-a$. The four groups of 30 comparisons, each at a fixed frequency were intermixed so as to distribute each frequency in about equal proportions over the 120 trials. After 60 trials, there was a 5- to 10-min break. At the end of the experiment, the $S$ filled out the same questionnaire as used in Experiment 1.

\section{Results}

The main findings are presented in Fig. 4 and Table 2. The results closely parallel those of Experiment 1. The average preference for intensity "peaks" at $50 \mathrm{~dB}$ and declines on either side. The curves at each frequency are shown in Fig. 5. The curve at $400 \mathrm{~Hz}$ is highest at $40 \mathrm{~dB}$ and declines regularly out to $90 \mathrm{~dB}$. The curves for the other three frequencies all peak at some intermediate value. The results in Table 2 show that the preferences of nine Ss peaked at some intermediate intensity and then declined on either side. Six Ss preferred the lowest intensity of $40 \mathrm{~dB}$ and had regularly declining preferences out to $90 \mathrm{~dB}$. One $S$, No. 14, again showed two "peaks."

The results were divided into four sets, one for the preferences at each frequency, and the same pattern of individual preferences was found as in Experiment 1 when the results were divided on the basis of stimulus intensity. That is, evidence for individual Ss having a preferred intermediate intensity was still present, although the curves were less consistent than when averaged across all four frequencies.

In Fig. 5 there is more evidence that at higher frequencies Ss preferred more intense tones. The curves for the different frequencies separate in a regular manner as frequency increases. The mean preferred intensity was $49.1 \mathrm{~dB}$ at $100 \mathrm{~Hz}$ and $59.1 \mathrm{~dB}$ at $5000 \mathrm{~Hz}$. This difference was quite significant $(\mathrm{t}=2.48, \quad \mathrm{p}<.02$, two-tailed, df $=15$. Again, no significant differences were found between high and low music Ss, between first and last trials, or between the sexes.

\section{DISCUSSION}

The general results constitute strong support for the initial hypotheses. However, there are several issues which require comment. An experiment by Singer and Young (1941) presents some evidence which does not agree with the results of Experiment 1. Singer and Young had Ss, in a group experiment. give pleasantness ratings of 18 pure tones ranging from 100 to $4000 \mathrm{~Hz}$. They found that pleasantness was highest, and roughly constant, from 100 to $500 \mathrm{~Hz}$, and declined thereafter. Thus, they failed to find that low tones were less preferred than moderate frequencies, e.g., 400-750 $\mathrm{Hz}$. [These data were used by Guilford (1954) to derive theoretical affective curves as a function of tone frequency.] There are, however, serious reasons to question the scaling procedure of Singer and Young. It is well known that ratings, in this case, rating tones on a scale from 0 to 110 , can often be misleading. In addition, the ratings were reduced to three gross categories: pleasant, indifferent, and unpleasant. The proportion of ratings in these three categories across all Ss were combined to create the published scale. For these reasons, it seems probable that the failure to detect a peak preference around 400 to $750 \mathrm{~Hz}$ is due to measurement weaknesses. Evidence to substantiate these criticisms comes from a study discovered after the present study was completed by Laird and Coye (1929). They presented frequencies ranging from 64 to $8192 \mathrm{~Hz}$ in a paired-comparison procedure and asked Ss which one of the two was more annoying. Their results agree closely with those presented here. The least annoying tones were 256,512 , and $1024 \mathrm{~Hz}$, while 64 and $128 \mathrm{~Hz}$ were very significantly more annoying, and were approximately equal in annoyance value to 2048 and 4098 , respectively; $8192 \mathrm{~Hz}$ was the most annoying of all. Thus, the case for a preferred level of tone frequency seems clear.

Another issue bearing on the results of Experiment 1 is the question of how the results of this experiment might have been affected by differences in loudness. From the Fletche $x-M u n s o n \quad\left(\begin{array}{llll}1 & 9 & 3 & 3\end{array}\right)$ equal-loudness curves, it is apparent that the differences between loudness and intensity are not especially great for 65 and $75 \mathrm{~dB}$, and are negligible

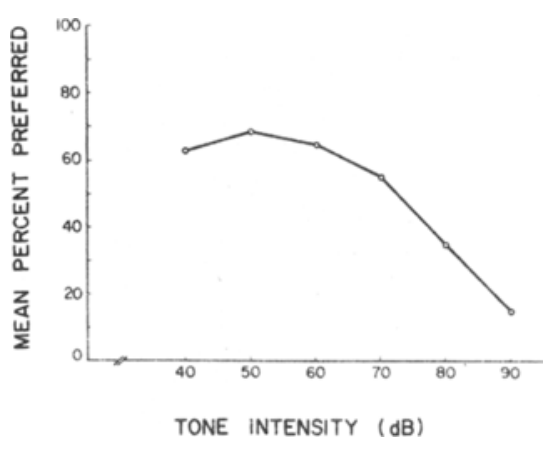

Fig. 4. Preference for tones as a function of tone intensity. Data points are the mean percent each tone was preferred in comparison to the cthers. 
Table 2

Percent Preference for Each Tone Intensity Averaged Across All Frequencies

Intensity (dB)

\begin{tabular}{|c|c|c|c|c|c|c|}
\hline \multirow[b]{2}{*}{$\mathbf{S}$} & \\
\hline & 40 & 50 & 60 & 70 & 80 & 90 \\
\hline 1 & 35.0 & 55.0 & 55.0 & 67.5 & 55.0 & 32.5 \\
\hline $\mathbf{2}$ & 37.5 & 62.5 & 62.5 & 72.5 & 40.0 & 25.0 \\
\hline 3 & 55.0 & 70.0 & 67.5 & 52.5 & 45.0 & 10.0 \\
\hline 4 & 70.0 & 80.0 & 80.0 & 47.5 & 22.5 & 0.0 \\
\hline 5 & 55.0 & 85.0 & 80.0 & 52.5 & 75.0 & 2.5 \\
\hline 6 & 75.0 & 75.0 & 75.0 & 50.0 & 21.0 & $\mathbf{0 . 0}$ \\
\hline 7 & 50.0 & 55.0 & 55.0 & 75.0 & 42.5 & 22.5 \\
\hline 8 & 92.5 & 72.5 & 62.5 & 40.0 & 27.5 & 5.0 \\
\hline 9 & 80.0 & 70.0 & 67.5 & 50.0 & 32.5 & 0.0 \\
\hline 10 & 27.5 & 67.5 & 67.5 & 75.0 & 45.0 & 17.5 \\
\hline 11 & 52.5 & 62.5 & 57.5 & 62.5 & 42.5 & 22.5 \\
\hline 12 & 95.0 & 77.5 & 60.0 & $\mathbf{4 5 . 0}$ & 20.0 & 2.5 \\
\hline 13 & 82.5 & 70.0 & 55.0 & 52.5 & 30.0 & 10.0 \\
\hline 14 & 55.0 & 52.5 & 47.5 & 40.0 & 42.5 & 62.5 \\
\hline 15 & 65.0 & 65.0 & 72.5 & 50.0 & 37.5 & 10.0 \\
\hline 16 & 80.0 & 75.0 & 70.0 & 47.5 & 22.5 & 5.0 \\
\hline $\begin{array}{l}\text { Mean } \\
\text { Percent }\end{array}$ & 62.9 & 68.4 & 64.7 & 55.0 & 34.7 & 14.2 \\
\hline
\end{tabular}

for $85 \mathrm{~dB}$. Therefore, it is likely that the affect of loudness is not apt to change the basic shape of the curve. Moreover, the middle values are those which are subjectively louder, and this presumably would have tended to work against the hypothesis.

The results of Experiment 2, a preferred intensity of approximately $50 \mathrm{~dB}$ (ranging from 40 to $60 \mathrm{~dB}$, depending on frequency), are somewhat lower than might be expected. Considerable previous work has been done on most comfortable listening levels (Pollack, 1952) and annoyance levels (Spieth, 1956). These studies typically have the $S$ listen to a single tone and adjust it, using the method of adjustment, to the most comfortable level or to a level which is almost annoying. In general, most comfortable listening levels and almost annoying tones are in the range from 60 to $95 \mathrm{~dB}$. The methodological differences between these studies and the present are large and make the results difficult to compare. For example, considerable adaptation is likely in using the method of adjustment, especially in comparison to the present procedure in which each tone lasted 1 sec. The questions asked the $S$ are different in important ways, and further, these experiments do not ask for comparisons between two frequencies and hence the important relative preferences are not determined.

Two Ss, S 9 in Table 1 and S 14 in Table 2, showed two peaks in their preference curves. This may be due to an artifart such as an unknown hearing weakness or gap. Nevertheless, such curves are very like the double peak or "butterfly" curves reported by Haber (1958), who found such curves of preference for discrepancies from a water-temperature adaptation level. In the present experiment, an $\mathrm{AL}$ might develop, as the experiment progressed, around the mean of the comparison stimuli and this could lead to double peak curves.

The finding that the preferred frequency went up when tone intensity increased (Experiment 1) and that the preferred intensity went up when frequency increased (Experiment 2) raises some problems. Although no prediction was made, the author expected that the opposite would be the case. The reasoning for this apparently false prediction is: if, for example, a S's preferred tone at $75 \mathrm{~dB}$ is $700 \mathrm{~Hz}$, then this can be interpreted as the S's optimal level of stimulation on both dimensions, i.e., total optimal stimulation. If the intensity is increased to $85 \mathrm{~dB}$, then presumably the $S$ would want to reduce the frequency, say to $600 \mathrm{~Hz}$, so as to remain close to the hypothesized total optimal stimulation. Instead of this compensatory shift, the opposite appears to be true-namely, that an increase or decrease on one dimension

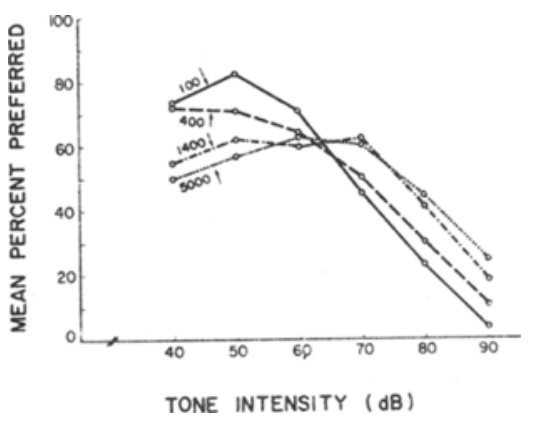

Fig. 5. Preference for tones as a function of tone intensity at four different levels of frequency (hertz). shifts the preference on the other dimension in the same direction. This result is difficult to interpret within the present theoretical framework. One possibly relevant observation is that when these results were mentioned to several musicians they were not surprised, since positively correlated changes in music are common, e.g., moving to a climax by increasing the loudness, pitch, and tempo.

An important issue raised by these results is the question of the physiological basis of such sensory pleasure. Although this issue has been largely ignored, there is a study by Berlyne, McDonnell, Nicki, and Parham (1967) that provides an interesting clue. Berlyne et al presented 1-sec tones of 200, 400, 800 , and $1600 \mathrm{~Hz}$ to Ss and recorded the duration of their EEG desynchronization. They found a $U$-shaped function in which desynchronization was least at $\mathbf{4 0 0}$ and $800 \mathrm{~Hz}$ and greatest at 200 and $1600 \mathrm{~Hz}$. These results are similar to those of Experiment 1 and raise the simple possibility that stimuli that cause desynchronous EEG are less pleasant than those that are associated with synchronous EEG. Such a simple relationship between judged preference or hedonic state and the EEG response is probably too simple in view of the known complexity of both variables -and yet it has enough plausibility to be given attention.

\section{REFERENCES}

BERLYNE, D. E, Conflict, arousal and curiosity, New York: McGraw-Hill, 1960. BERLY NE, D. E. Arousal and reinforcement. In $D$. Levine (Ed.), Nebraska symposium on motivation 1967. Lincoln: University of Nebraska Press, 1967

BERLYNE, D. E., MCDONNELL, P.. NICKI, R. M. \& PARHAM, L. C. C. Effects of auditory pitch and complexity on EEG desynchronization and on verbally expressed judgments. Canadian Journal of Psychology, 1967, 21 . 346-367

BOESCH, E. E, BALTES, P. B., \& SCHMIDT, L. R. Preference for different auditory stimulus sequences in various age groups. Psychonomic Science, 1968, $10,205-206$.

DEMBER, W. N., \& EARL, R. W, Analysis of exploratory, manipulatory and curiosity behaviors. Psychological Review, 1957, 64, 329-339.

ENGLE, R. Experimentelle Untersuchungen über die Abhangigkeit der Lust und Unlust von der Reizstarke beim Geschmacksinn. Archiv für die gesamte Psychologie, 1928, 64, 1-36. Cited by Woodworth, R. S., \& Schlosberg, H. Experimental Psychology. New York Holt, 1954.

FISKE, D. W., \& MADDI, S. R. Functions of varied experience. Homewood, il: Dorsey, 1961 .

FLETCHER, H., \& MUNSON, W. A. Loudness, its definition, measurement and calculation. Journal of the Acoustical Society of America, 1933, 5, 82-108.

GUILFORD, J. P. System in the relationship of affective value to 
frequency and intensity of auditory stimuli. American Journal of Psychology, 1954,67,691-695.

HABER, R. N. Discrepancy from adaptation level as a source of affect. Joumal of Experimental Psychology, 1958, 56, 370-375.

LAIRD, D. A., \& COYE, K. Psychological measurements of annoyance as related to pitch and loudness. Journal of the Acoustical Society of America, 1929, 1, 158-163.

PFAFFMANN, C. The pleasures of sensation. Psychological Review, 1960, $67,253-268$.

POLLACK, I. Comfortable listening levels for pure tones in quiet and noise. Journal of the Acoustical Society of America $1952,24,158-162$.

SCHNEIRLA, T. C. An evolutionary and developmental theory of biphasic processes underlying approach and withdrawal. In M. R. Tones (Ed) Nebraska symposium on motivation 1959. Lincoln: University of Nebraska Press, 1959.

SCHNEIRLA, T. C. Aspects of stimulation and organization in approach withdrawal processes underlying vertibrate behavioral development. In D. L. Lehrman, $R$. Hinde, and E. Shaw (Eds.), Advances in the study of behavior. New York: Academic Press, 1965

SINGER, W. B., \& YOUNG, P. T. Studies in affective reaction: II Dependence of affective ratings upon the stimulus-situation. Journal of General Psychology, 1941, 24, 303-325.

SPIETH, W. Annoy ance threshold judgements of bands of noise. Journal of the Acoustical Society of America, 1956, 28, 872-877.

STEVENS, S. S. On the psychophysical law. Psychological Review, 1957, 64, 153-181. VITZ, P. C. Affect as a function of stimulus variation. Journal of Experimental Psychology, 1966, 71, 74-79.

WUNDT, W. Grundzuge der physiologischen Psychologie. Leipzig: Engelmann, 1874.

(Accepted for publication June 10, 1971.) 